\title{
EVALUATION OF THE EFFECT OF CALCIUM HYDROXIDE AND ENDODONTIC IRRIGANTS ON THE PUSH-OUT BOND STRENGTH OF FIBER POST - AN IN VITRO STUDY
}

\author{
ANJUM CHAUDHARY, MOHIT KUMAR, SONALI TANEJA
}

\author{
Department of Conservative Dentistry and Endodontics, ITS Dental College, \\ Muradnagar, Ghaziabad, India
}

\section{Abstract}

Background. In recent years, fibre-reinforced composite posts have been proposed for the restoration of root filled teeth as an alternative to pre-fabricated posts or metal dowels.

Aims and objectives. The aim of the study was to analyze the effect of endodontic irrigants used for removal of calcium hydroxide on the push-out bond strength of fiber posts to root canal dentin.

Methods. Forty human permanent single-rooted mandibular premolars with relatively straight roots were taken and access cavities were prepared and biomechanical preparation done using Rotar Y protaper file till size F2. The samples were divided into Experimental group and Control group. In Experimental groups Intracanal dressing of calcium hydroxide was removed by $2.5 \% \mathrm{NaOCl}$ and $17 \%$ EDTA (Group1), MTAD (Group II) and Qmix (Group III). Control group did not receive Intracanal calcium hydroxide dressing. Canals were obturated using size F2 protaper gutta-percha points and AH plus sealer. After storage for 24 hours, post space was prepared. Forty Tenax fiber post (Coltene) were cemented with Rely X U200 resin. The roots were then transversally sectioned into 3 slices of $1 \mathrm{~mm}$ thickness corresponding to cervical, middle and apical third. The slices obtained were subjected to micro-push-out bond strength test using a universal testing machine. The data obtained was subjected to statistical analysis using One-Way ANOVA test. P value of .05 was considered as statistically significant level.

Results. The mean push-out bond strength values for controls, NaOCl/EDTA, MTAD and QMIX group at cervical third were 10.17, 15.84, 20.39 and 20.98 whereas at apical third 4.78, 8.85, 11.66 and 12.10 .

Conclusion. Qmix showed higher push-out bond strength values followed by MTAD and NaOCl/EDTA. All the groups showed lowest push-out bond strength values in the apical third followed by middle and the maximum in the cervical region.

Keywords: fiber post, Qmix, irrigants, calcium hydroxide

\section{Background}

Endodontically treated teeth often have insufficient remaining coronal structure to retain restorative materials and a post is often required to provide adequate retention for the core.

In recent years, fibre-reinforced composite posts have been proposed for the restoration of root filled teeth as an alternative to pre-fabricated posts or metal dowels [1]. The main advantage of fibre posts is that their modulus of elasticity is close to dentin, reducing stress transmission to

Manuscript received: 19.02.2018

Accepted: 07.03.2018

Address for correspondence: mohit_cusp@yahoo.co.in root canal walls and the risk of vertical fracture [2].

In addition, endodontic procedures performed before the luting of posts may interfere with bonding to root canal walls $[3,4]$. Several factors affecting the quality of adhesion at the dentine-cement-post interfaces include the post space preparation, presence and thickness of the endodontic smear layer, effect of different chemicals used such as root canal irrigants and/or endodontic filling materials which clearly modify dentin substrate.

The success of endodontic treatment is determined by elimination of endodontic infection. Although instrumentation procedures have improved over the years, none of the existing techniques or methods can completely clean the root 
canal system [5]. Therefore, an intracanal medicament with profound antibacterial activity against most of the bacterial strains identified in root canal infections is required [6,7]. Amongst them, calcium hydroxide $(\mathrm{CH})$ mixed with an appropriate vehicle left in the root canal for several days or weeks, has been widely accepted in endodontic therapy [7,8].

The removal of Calcium hydroxide from the root canal has been investigated using a wide range of products and techniques $[9,10,11,12,13,14]$. The most frequently used method is instrumentation of the root canal using a master apical file (MAF) and copious irrigation with a combination of sodium hypochlorite $(\mathrm{NaOCl})$ and $17 \%$ EDTA [10].

Recently, QMix (Dentsply Tulsa Dental, Tulsa, OK, USA), a novel irrigant for smear layer removal with an adjunct antimicrobial agents, has been developed. It is composed of EDTA, CHX and a surfactant. Another recently introduced irrigant, MTAD, is a mixture of doxycycline, citric acid and Tween 80. Due to one of its constituent, i.e. citric acid, it has a high acidic capacity $(\mathrm{pH}=2)$ [15]. This acidic property acts as an etchant agent that can efficiently remove the mineral contents of smear layer.

None of the previous studies have evaluated the effect of these irrigants when used for removal of intracanal dressing of $\mathrm{Ca}(\mathrm{OH})_{2}$ / distilled water.

Therefore, the purpose of the study was to analyze the effect of $\mathrm{NaOCl} / \mathrm{EDTA}$, MTAD and QMIX used for removal of calcium hydroxide on the push out bond strength of fiber posts to root canal dentine.

\section{Aims and objectives}

The aim of the study was to analyse the effect of endodontic irrigants used for removal of calcium hydroxide on the push-out bond strength of fiber posts to root canal dentine.

\section{Materials and methods \\ Selection of samples}

Forty human permanent single- rooted mandibular premolar with relatively straight roots and fully formed apices freshly extracted for orthodontic or periodontal reasons were used for the study.

\section{Preparation of sample}

Access cavities were prepared by using Endo-access bur (Dentsply Maillefer), the teeth were then decoronated with a low-speed handpiece and diamond discs under water coolant to obtain a standardized length of $17 \mathrm{~mm}$ for all the roots. Working length of $16 \mathrm{~mm}$ was achieved for each tooth by subtracting $1 \mathrm{~mm}$ from final dimension i.e. $17 \mathrm{~mm}$. Biomechanical preparation was done using protaper rotary instruments till size F2.

All the samples were randomly divided into three experimental groups and one control group. The specimens in experimental group received an intracanal dressing of $\mathrm{Ca}(\mathrm{OH})_{2} /$ distilled water for one week and were irrigated with respective irrigant for its removal while those in control group did not receive intracanal dressing of $\mathrm{Ca}(\mathrm{OH})_{2} /$ distilled water and irrigated with distilled water.

All the canals were obturated using the single cone technique with size F2 ProTaper gutta-percha points and AH plus sealer. After storage for 24 hours, the root canals were prepared to ensure a standardized space for post insertion.

\section{Surface treatment and cementation of post}

Forty Tenax fibre post having length $19 \mathrm{~mm}$ and diameter $1.1 \mathrm{~mm}$ were cleaned with $100 \%$ alcohol and coated with a silane coupling agent, which was applied with microbrush and air-dried.

Root canals were water rinsed and excess moisture was removed with absorbent paper points before the luting procedure. Then RelyX U200 cement was hand mixed for 10 seconds. Post was then inserted into the post space. Excess cement was removed and light cured for 40 seconds through the fiber post

After this all post-cemented roots were placed in $100 \%$ relative humidity at $37^{\circ} \mathrm{C}$ for 24 hours before testing. The roots were then transversally sectioned into three slices and push out bond strength was tested using Universal Testing Machine.

\section{Statistical analysis}

The data obtained was subjected to statistical analysis using SPSS Version 15.0 statistical Analysis Software. One-way ANOVA test was applied to check the significant difference between the groups and Repeated measures ANOVA test to check the significance within the group. The Bonferroni post hoc test was used for analysis for comparison of means. P value of 0.05 has been considered as statistically significant level.

\section{Results}

The mean push-out bond strength values for control group at cervical, middle and apical third were $10.17 \pm 0.53$, $6.21 \pm 0.50$ and $4.78 \pm 0.39$ respectively, for the $\mathrm{NaOCl} /$ EDTA group were $15.84 \pm 0.46,12.22 \pm 0.47$ and $8.85 \pm 0.40$, for the MTAD group were $20.39 \pm 0.43,16.15 \pm 0.29$ and $11.66 \pm 0.40$, and for QMIX group were $20.98 \pm 0.73$, $16.98 \pm 0.30$ and $12.10 \pm 0.52$ respectively (Table I).

Table I. showing the mean push-out bond strength values of all groups at different root third level.

Table I. Irrigation regiment

\begin{tabular}{|l|l|l|l|l|}
\hline Root Level & Distilled water & $\mathrm{NaOCl} / \mathrm{EDTA}$ & MTAD & Qmix \\
\hline CORONAL & $10.17 \pm 0.53^{\mathrm{Aa}}$ & $15.84 \pm 0.46^{\text {Bab }}$ & $20.39 \pm 0.43^{\text {Cabc }}$ & $20.98 \pm 0.73^{\text {Dabc }}$ \\
\hline MIDDLE & $6.21 \pm 0.50^{\mathrm{Aa}}$ & $12.22 \pm 0.47^{\text {Bab }}$ & $16.15 \pm 0.29^{\text {Cabc }}$ & $16.98 \pm 0.30^{\text {Dabc }}$ \\
\hline APICAL & $4.78 \pm 0.39^{\text {Aa }}$ & $8.85 \pm 0.40^{\text {Bab }}$ & $11.66 \pm 0.40^{\text {Cabc }}$ & $12.10 \pm 0.52^{\text {Dabc }}$ \\
\hline
\end{tabular}

Same superscripts in capital letters denotes significant difference across column while same superscripts in small letter denotes significant difference rows. 


\section{Dental Medicine}

All the groups showed lowest push-out bond strength values in the apical third followed by middle and the maximum in the cervical third region and the difference between them were statistically significant.

Qmix showed higher push-out bond strength values than Control and $\mathrm{NaOCl} /$ EDTA groups at all regions and the difference between them was statistically significant. Qmix also showed higher push-out bond strength values than MTAD group, but the difference between them was not statistically significant.

\section{Discussion}

In accordance with the result of the study, null hypothesis was rejected as there was difference in the pushout bond strength of fibre post in Control group, NaOCL/ EDTA group, MTAD group and Qmix group in different regions of the specimen.

Intergroup comparison revealed that Qmix showed higher push-out bond strength values than $\mathrm{NaOCl}$ /EDTA and Control group at all root regions, the difference between them were statistically significant. The highest bond strength in Qmix group could be attributed to its composition which enhances the demineralization of radicular dentine due to the chelating effect of EDTA and the presence of surfactant which lowers the surface tension and increases its wettability both of which in turn might have led to better removal of $\mathrm{Ca}(\mathrm{OH})_{2}$ from the root canal, which might have resulted in better removal of obturating material leaving no residues of $\mathrm{Ca}(\mathrm{OH})$ on the walls and resulting in high bond strength.

No previous studies have evaluated the efficacy of Qmix in removal of $\mathrm{Ca}(\mathrm{OH})_{2}$ dressing. However, many studies evaluating its efficacy in removal of smear layer have found it to be quite effective.

Tasman et al. (2000) [16] have reported that EDTA solution in QMIX has a relatively low surface tension, which might improve the dentin wettability.

Eliot et al. (2013) [17] have shown that QMix endodontic irrigant is an effective irrigant that can remove the smear layer, open the dentinal tubules for disinfection and simplify the irrigation protocol without compromising the bonding strength of glass fibre posts cemented with self-adhesive resin cement to root dentine.

Qmix showed a higher push-out bond strength values than MTAD group but was not statistically significant.

This could be due to their comparable efficacy in smear layer removal as reported by Dai et al [18]. Intergroup comparison revealed that MTAD showed higher pushout bond strength values than $\mathrm{NaOCl} / \mathrm{EDTA}$ and Control group at all root regions, the difference between them being statistically significant. The higher bond strength values could be due to the presence of doxycycline, citric acid and the detergent Tween 80. The detergent in MTAD lowers the surface tension and increases the dentin wettability [15] while citric acid in MTAD, has high acidic capacity $(\mathrm{PH} \approx 2)$ which acts as an etchant agent that can effectively remove the mineral contents of smear layer [19].

In the present study $\mathrm{NaOCl} / \mathrm{EDTA}$ showed higher push-out bond strength values than control group at all root regions, the difference between them were statistically significant. This could be due to better removal of intracanal dressing of $\mathrm{Ca}(\mathrm{OH})_{2}$ in $\mathrm{NaOCl} /$ EDTA group as compared to control group.

Sodium hypochlorite acts upon organic components (mainly collagens) of the dentine and improves the penetration of monomers into the dentine structure $[20,21,22]$. While EDTA demineralizes dentin, cleans canal walls well, improves the action of chemical substances and promotes closer contact of the filling material with the root dentine $[21,22,23,24]$.

Renovato et al. (2013) [25] reported lower push-out bond strength in $\mathrm{NaOCl} / \mathrm{EDTA}$ group which was used to remove the $\mathrm{Ca}(\mathrm{OH})_{2}$ dressing immediately from the root canal when compared to $\mathrm{NaOCl}$ group. The authors found that lower bond strength could be because of the fact EDTA acts on the inorganic components of the smear layer and decalcifies peritubular and intertubular dentine. It also binds covalently to metal ions and sequesters calcium ions present in the hydroxyapatite of dentine [24].

Intragroup comparison in all the groups revealed that the lowest bond strength was observed in the apical third followed by middle and maximum in the cervical region and the difference between them was statistically significant. The results were in accordance with many previous reported studies.

The decrease in bond strength in the apical third may be explained by the presence of calcium hydroxide left in the root canal walls after medication, mainly in the apical third $[10,26]$.

Our study clearly demonstrates the superior bond strength of fibre glass post when calcium hydroxide removal was done using novel irrigants like QMIX and MTAD. Further studies are required to evaluate the amount of calcium hydroxide remaining in the root canal after irrigation with these irrigants.

\section{Conclussion}

Within the limitation of the study it was found out that the push-out bond strength of fibre post to root canal dentin was highest in the QMIX group followed by MTAD and $\mathrm{NaOCl} / \mathrm{EDTA}$ and the least was exhibited by the Control group.

\section{References}

1. Cagidiaco MC, Radovic I, Simonetti M, Tay F, Ferrari M. Clinical performance of fiber post restorations in endodontically treated teeth: 2-year results. Int J Prosthodont. 2007;20:293-298. 2. Asmussen E, Peutzfeldt A, Heitmann T. Stiffness, elastic limit, and strength of newer types of endodontic posts. J Dent. 1999;27:275-278.

3. Ari H, Yaşar E, Belli S. Effects of $\mathrm{NaOCl}$ on bond strengths of 
resin cements to root canal dentin. J Endod. 2003;29:248-251. 4. Muniz L, Mathias P. The influence of sodium hypochlorite and root canal sealers on post retention in different dentin regions. Oper Dent. 2005;30:533-539.

5. Hülsmann M, Peters OA, Dummer PMH. Mechanical preparation of root canals: shaping goals, techniques and means. Endod Topics. 2005;10:30-76.

6. Siqueira JF Jr, Lopes HP. Mechanisms of antimicrobial activity of calcium hydroxide: a critical review. Int Endod J. 1999;32:361369.

7. Lee M, Winkler J, Hartwell G, Stewart J, Caine R. Current trends in endodontic practice: emergency treatments and technological armamentarium. J Endod. 2009;35:35-39.

8. Fava LR, Saunders WP. Calcium hydroxide pastes: classification and clinical indications. Int Endod J. 1999;32:257-282.

9. Nandini S, Velmurugan N, Kandaswamy D. Removal efficiency of calcium hydroxide intracanal medicament with two calcium chelators: volumetric analysis using spiral CT- an in vitro study. J Endod. 2006;32:1097-1101.

10. Lambrianidis T, Margelos J, Beltes P. Removal efficiency of calcium hydroxide dressing from the root canal. J Endod. 1999;25:85-88.

11. Lambrianidis T, Kosti E, Boutsioukis C, Mazinis M. Removal efficacy of various calcium hydroxide/chlorhexidine medicaments from the root canal. Int Endod J. 2006;39:55-61.

12. Kenee DM, Allemang JD, Johnson JD, Hellstein J, Nichol BK. A quantitative assessment of efficacy of various calcium hydroxide removal techniques. J Endod. 2006;32:563-565.

13. van der Sluis LW, Wu MK, Wesselink PR. The evaluation of removal of calcium hydroxide paste from an artificial standardized groove in the apical root canal using different irrigation methodologies. Int Endod J. 2007;40:52-57.

14. Salgado RJ, Moura-Netto C, Yamazaki AK, Cardoso LN, de Moura AA, Prokopowitsch I. Comparison of different irrigants on calcium hydroxide medication removal: microscopic cleanliness evaluation. Oral Surg Oral Med Oral Pathol Oral Radiol Endod. 2009; 107:580-584.

15. Barkhordar RA, Watanabe LG, Marshall GW, Hussain MZ. Removal of intracanal smears by doxycycline in vitro. Oral Surg Oral Med Oral Pathol Oral Radiol Endod. 1997;84:420-423.
16. Taşman F, Cehreli ZC, Oğan C, Etikan I . Surface tension of root canal irrigants. J Endod. 2000;26:586-587.

17. Eliot C, Hatton JF, Stewart GP, Hildebolt CF, Jane Gillespie M, Gutmann JL . The effect of the irrigant QMix on removal of canal wall smear layer: an ex vivo study. Odontology. 2014;102:232240 .

18. Dai L, Khechen K, Khan S, Gillen B, Loushine BA, Wimmer CE, et al. The effect of QMIX, an experimental antibacterial root canal irrigant, on removal of canal wall smear layer and debris. J Endod. 2011;37:80-84.

19. Torabinejad M, Khademi AA, Babagoli J, Cho Y, Johnson WB, Bozhilov K, et al. A new solution for the removal of smear layer. J Endod. 2003;29:170-175.

20. Dietschi D, Duc O, Krejci I, Sadan A. Biomechanical considerations for the restoration of endodontically treated teeth: a systematic review of the literature--Part 1. Composition and micro- and macrostructure alterations. Quintessence Int. 2007;38:733-743.

21. Demiryürek EO, Külünk S, Saraç D, Yükssel G, Bulucu B. Effect of different surface treatments on the push-out bond strength of fibre post to root canal dentin. Oral Surg Oral Med Oral Pathol Oral Radiol Endod. 2009;108:e74-e80.

22. Moreira DM, Almeida JF, Ferraz CC, Gomes BP, Line SR, Zaia AA. Structural analysis of bovine root dentin after use of different endodontics auxiliary chemical substances. J Endod. 2009;35:1023-1027.

23. Hülsmann M, Heckendorff M, Lennon A. Chelating agents in root canal treatment: mode of action and indications for their use. Int Endod J. 2003;36:810-830.

24. Renovato SR, Santana FR, Ferreira JM, Souza JB, Soares CJ, Estrela C. Effect of calcium hydroxide and endodontic irrigants on fibre post bond strength to root canal dentine. Int Endod J. 2013;46:738-746.

25. Cecchin D, Farina AP, Galafassi D, Barbizam JV, Corona SA, Carlini-Júnior B Influence of sodium hypochlorite and EDTA on the microtensile bond strength of a self-etching adhesive system. J Appl Oral Sci. 2010;18:385-389.

26. Balvedi RP, Versiani MA, Manna FF, Biffi JC. A comparison of two techniques for the removal of calcium hydroxide from root canals. Int Endod J. 2010;43:763-768. 